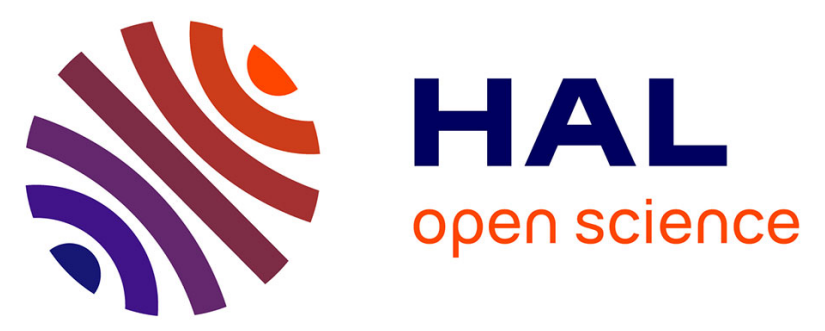

\title{
Simulation of morphological plasticity of Acacia tortilis in response to herbivore attacks
}

\author{
Amélie Mathieu, Véronique Letort, Renaud Gosset, Jacques Gignoux, \\ Paul-Henry Cournède
}

\section{- To cite this version:}

Amélie Mathieu, Véronique Letort, Renaud Gosset, Jacques Gignoux, Paul-Henry Cournède. Simulation of morphological plasticity of Acacia tortilis in response to herbivore attacks. Third International Symposium on Plant Growth Modeling, Simulation, Visualization and Applications (PMA09), Saisissez le nom du laboratoire, du service ou du département., Ville service., 2009, Beijing, China. 454 p. inria-00543136

\author{
HAL Id: inria-00543136 \\ https://inria.hal.science/inria-00543136
}

Submitted on 5 Dec 2010

HAL is a multi-disciplinary open access archive for the deposit and dissemination of scientific research documents, whether they are published or not. The documents may come from teaching and research institutions in France or abroad, or from public or private research centers.
L'archive ouverte pluridisciplinaire HAL, est destinée au dépôt et à la diffusion de documents scientifiques de niveau recherche, publiés ou non, émanant des établissements d'enseignement et de recherche français ou étrangers, des laboratoires publics ou privés. 


\title{
Simulation of morphological plasticity of Acacia tortilis in response to herbivore attacks
}

\author{
Amélie Mathieu ${ }^{1,2, *}$, Véronique Letort ${ }^{1, *}$, Renaud Gosset $^{3}$, Jacques Gignoux $^{4}$, Paul-Henry Cournède $^{1}$ \\ ${ }^{1}$ Ecole Centrale de Paris, Laboratoire MAS, Chatenay Malabry, France \\ ${ }^{2}$ AgroParisTech, UMR ECG INRA-AgroParisTech, Thiverval Grignon, France \\ ${ }^{3}$ INRIA Saclay IdF, EPI Digiplante, Orsay, France \\ ${ }^{4}$ ENS, Bioemco, Paris, France \\ * corresponding authors: amelie.mathieu@agroparistech.fr, veronique.letort@ecp.fr
}

\begin{abstract}
Understanding tree architectural plasticity is a major challenge. Functional-structural models can be of great interest to quantify the allocation patterns and their changes according to environment.

In this paper, we focus on Acacia tortilis trees in savanna to understand their responses to herbivore attacks both in terms of architecture and allocation pattern. Measurements were carried out in Hwange National Park (Zimbabwe) in 2008. Architectural and biomass data were analysed to quantify the effects of herbivore attacks on plant morphogenesis, and trees were gathered in two groups depending on the intensity of herbivore attacks they suffered. Based on these results, a simple model of herbivore attacks has been implemented and parameters have been estimated in the framework of the GreenLab model and we simulate different realistic behaviours according to the intensity of herbivore attacks.
\end{abstract}

\section{Introduction}

Savanna is a very heterogenous environment where trees are subject to diverse constraints such as fire, hydric stress or herbivore attacks. Trees express a high degree of morphological plasticity due to the variability of the constraints they are subject to. Inside a monospecific population, depending on its environmental constraints, an individual may either develop an intensively branched architecture in order to protect itself against herbivore attacks or conversely invest in underground storage organs to ensure its survival against fire [11],[4]. The observed morphological diversity cannot be explained by genetic differences [5] as the savanna constraints evolve too quickly compared to the time characteristic for natural selection [1].

In this paper, we aim at studying the different strategies trees use to survive in such environment and we focus on the Acacia tortilis. Several studies were conducted on the architectural response of acacia to external constraints [2], [15], but only few of them were concerned with the modification of the allocation pattern mainly because of the experimental difficulty to measure carbon allocation to organs. Quantifying the allocation remains a challenge in ecology and functional-structural models of plant growth can be powerful tools to access these hidden variables.

In the South Africa savanna, the amount of wood a tree produces depends on its environment [8],[12]. Plant is the result of balanced allocation between vegetative and reproductive parts [14] or between aerial and underground parts [19]. For example, young Acacia karroo subject to pruning will compensate by allocating less biomass to branches but keeping up biomass allocation to leaves [18].

Trees were measured in Zimbabwe in 2008 and characterized according to the intensity of the herbivore attacks they have suffered. We first present a statistical analysis of data to estimate the effects of attacks on plant growth. we deduce the parameters of the GreenLab model, which allows us to reproduce the growth and development of plants. A specific version of the model has been developed to reproduce herbivore attacks and we present simulations of the effects of herbivore attacks on virtual plants.

\section{Materials and Methods}

\subsection{Measurements}

Acacia tortillis were measured in the wildlife reserve of Hwange (18 $30^{\prime}-19^{\circ} 53^{\prime} \mathrm{S}, 2^{\circ} 48^{\prime}-27^{\circ} 27^{\prime} \mathrm{E}$, Zimbabwe) in April 2008. The selected tree species, Acacia tortilis, is 
one of the dominating species of this area. Its complex architecture varies according to tree developmental stage and environment. Leaves are relatively short and pinnate.

In order to estimate the impacts of herbivore attacks on plant morphogenesis, we selected seven young trees that are more sensitive to attacks. Measured trees were characterized according to the proportion of live apices on the total number of apices and distributed in two populations (see table 2.1). We assume that this variable is correlated to the intensity of the herbivore attacks that depends on the location of the tree (distance to village, protection by fences). Both

\section{Table 1. Distribution of the individuals in two populations and their proportion of live apices according to their total number of apices. Population $L$ : low intensity of at- tacks. Population $H$ : standard intensity of attacks.}

\begin{tabular}{lccccccc}
\hline Plant number & S1 & S2 & S3 & S4 & S5 & S6 & S7 \\
\hline $\begin{array}{l}\text { Proportion } \\
\text { of live apices }\end{array}$ & - & 0.46 & 0.26 & 0.15 & 0.22 & 0.18 & 0.50 \\
\hline Population & L & L & H & H & H & H & L \\
\hline
\end{tabular}

architecture and biomasses were measured on the sampled trees. For the aerial part, detailed measurements of axes of order 1 and 2 were carried out: lengths and masses of internodes, branch position. For the axes of order 3, the number of internodes and the number of lateral axes were counted. The blade surfaces and dry masses were measured for some axes. Due to its depth, the root system was only partly dug up (up to $40 \mathrm{~cm}$ ), and its total mass was deduced from the weighted mass. Besides, five branches, denoted by $E 1, E 2, E 5, E 10, E 11$, were sampled on other trees protected from herbivore attacks to understand variability within the population $L$. For each blade and internode, dry mass and dimensions were recorded.

\subsection{The GreenLab model}

We recall in this section the main principles of the GreenLab model. A more detailed description can be found in [7]. This model has already been calibrated for real trees with complex architecture, c.f. [16] for an example.

The tree growth is represented with a discrete time step that is the time needed to build a new phytomer. A phytomer is an internode with a main leaf, spines or hooks at its basis and small axillary leaves. A growth unit $(G U)$ is a cohort of organs appearing together on the same axis. At each time step, the number of new organs is given by mathematical rules [7] and plant architecture is built with geometrical rules. For the acacia trees, we gather the different phytomers into categories, called the physiological ages, according to their morphological properties: the phytomers of the trunk, respectively the large branches and the twigs, are of physiological age 1 , respectively 2 and 3 .

At time step $n$, the biomass $Q(n)$ produced by the tree is computed with an empirical equation based on the BeerLambert law with extinction coefficient $k$ :

$$
Q(n)=E(n) \mu S_{p}\left(1-e^{-k \frac{S(n)}{S_{p}}}\right)
$$

$S(n)$ is the total plant leaf area at time step $n, E(n)$ is proportional to the photosynthetically active radiation received by the plant during the time step, $S_{p}$ is inversely proportional to the stand density and $\mu$ is an efficiency.

This amount of biomass is allocated to plant organs with a proportional model. Each organ receives an amount of biomass proportional to its sink strength multiplied by the total available biomass $Q(n)$ divided by the plant demand $D(n)$, that is the sum of all the sink strengths. A proportion $p_{R}$ of biomass is allocated to the root system.

The ratio of biomass to demand $(Q(n) / D(n))$ is a convenient variable to describe the feedbacks between functional mechanisms and plant development [17]. In the model, it controls the number of new phytomers and branches. For the acacia tree, we use a simple model allowing delayed starting of buds, i.e. buds may remain dormant during $\tau$ time steps and start only if the ratio of biomass to demand is high enough (see equation 2). We assume that young buds are favored and old buds eventually die after $\tau$ time steps of dormancy. $b_{p}(t, n)$ denotes the number of buds of physiological age $p$ that appeared at time step $n$ but starts at time step $t, \alpha_{p}, \beta_{p}, \gamma_{p}$ are parameters of the model, with $\gamma_{p}<1$ and $\lfloor x\rfloor$ is the integer part of $x$. We write the equation for $t-n+1<\tau$ :

$$
b_{p}(t, n)=\left\lfloor\left(\alpha_{p}+\beta_{p} \frac{Q(t-1)}{D(t-1)}\right) * \gamma_{p}^{t-n+1}\right\rfloor
$$

\subsection{Modelling attacks of herbivores}

Herbivore attacks were modelled based on field observations and existing models [20],[10]. Animals will primarily address the young and accessible leaves and stems. Since the studied plants are young and rather small, we suppose that the probability for a phytomer to be eaten does not depend on its height in plant architecture. This parameter could not be neglected for bigger trees. In the GreenLab model, for each physiological age, herbivore attacks are supposed to depend on three input parameters:

- Number of terminal $G U$ eaten at each attack. The apex of an eaten axis is assumed to be dead.

- Age at which the $G U$ can not be eaten anymore, because herbivores attack primarily young $G U$.

- Time steps of attack. As we found few data on the frequency of attacks, we set it as an input parameter. 
After a strong attack, the tree is assumed to be able to remoblize biomass from the root system. This behaviour is typically observed for acacia tree subject to high environmental constraints. In the model, if the ratio of available biomass to demand $(Q / D)$ is under a given threshold parameter, a constant proportion of root biomass will be remobilized and allocated to the aerial part of the tree.

\section{Results}

To quantify changes in plant morphogenesis due to herbivore attacks, some architectural variables were analysed.

\subsection{Internodes}

An analysis of variance on lengths of trunk internodes showed a high effect of the individual on the internode length (Pvalue $<0.001$ ). It could not be linked to the intensity of the attack the tree suffered. Conversely, for young terminal branches, analysis of variance showed an influence of the herbivore attack on internode length (Pvalue = 0.003). Internodes of trees subject to low intensity attacks are significantly higher than similar internodes in population $H$. Individuals not stressed by attacks seems to invest more in primary growth. This result is coherent with recent studies: trees recently protected from attacks were shown to produce greater shoots [3] and removing leaves on young acacia trees induces shorter $G U$ [6].

Furthermore, data analysis show that the secondary growth is coherent with the pipe model theory but this process seems to be unaffected by the attacks (no significative differences between the populations).

\subsection{Leaf masses and surfaces}

At the individual scale, the linear relationship between leaf mass and leaf surface is a very good approximation $\left(R^{2}>0.9\right.$ for our data set). There is no significant difference in specific leaf mass (SLM) between main leaves and axillary ones. But the SLM is significantly lower for trees of population $L$ compared to population $H$ (Fig. 3.2). An analysis of variance shows that leaf surfaces are smaller for individuals of population $H$ with a mean value of $1.2 \mathrm{~cm}^{2}$ to be compared to the mean value for population $L$ of $2.4 \mathrm{~cm}^{2}$. This may be because the larger leaves were recently eaten on attacked trees, and only the smaller ones remained on the trees.

\subsection{Parameter estimation}

We use our data to estimate parameters of source and sink strength functions to model the growth of acacia trees, although we are aware of the great variability of these values inside the sampled population.

Observations show that leaves stay on trees for about 20

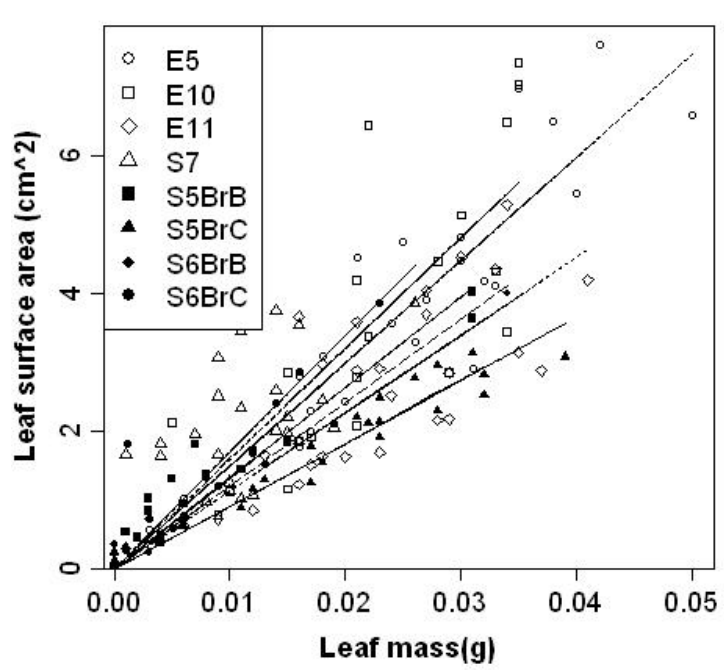

Figure 1. Relationships between mass and surfaces. Closed symbols:population $H$, open symbols:population $L$

time steps. For the sake of simplicity, we assume that their sink strength is constant during whole growth (10 time steps). The leaf sink strength is set to 1 , and the internode sink strength is 0.8 , value given by calibration on real data with methods presented in [13]. As we do not have data on root growth dynamics, we suppose that the root compartment receives $30 \%$ of the biomass produced at each cycle, that is the mean experimental value.

Regarding the source strength, the model calibration gives $\mu=30$ and we assume that trees do not suffer from stand competition with other trees, hence $S_{p}=10 \mathrm{~m}^{2}$.

Difference in internode size between the two populations is incorporated by defining geometrical rules: for the same amount of biomass, an internode of population $L$ will be longer but narrower compared to one of population $H$.

\subsection{Simulation}

From parameter estimation, we simulate typical plant growths for trees protected from herbivores (Fig 3.4a) or not (Fig 3.4b). The attack stops the growth of the terminal axis, and the one is relayed by dormant lateral buds. Attacked tree grows rather in width than in height, and has less phytomers the protected ones because, in our example, dormant buds do not suffice to fully compensate losses.

\section{Discussion}

Recent progress in structural functional plant growth models offer new possibilities for exploration in ecology 


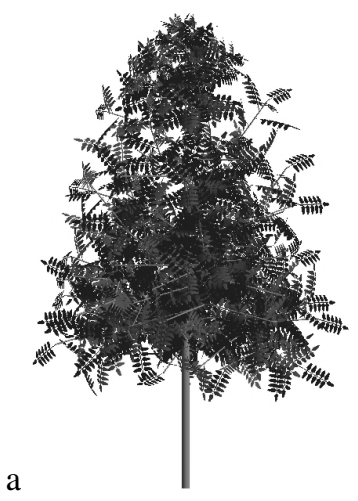

b

Figure 2. Simulation of acacia trees. a: tree protected from herbivore attacks, b: tree attacked three times $(8,14,20$ time steps). Both trees are represented at 25 time steps.

[9]. This paper presents the coupling of an individual plant model with a simple model of herbivore attacks. Experimental data allow us to estimate GreenLab model parameters and reproduce tree growth, with architectural changes according to the intensity of herbivore attacks. However, due to the experimental design, the quantification of the attack intensity is not very precise. Thus measurements should be completed with data on plant growth dynamics. Likewise, definitions of the level of attack intensity should be refined, to allow us to validate this model more thoroughly.

\section{Acknowledgement}

This research is supported by the ANR project 3 Worlds.

\section{References}

[1] L. Abbadie, J. Gignoux, X. Le Roux, and M. Lepage. Lamto : Structure, Functioning, and Dynamics of a Savanna Ecosystem. Ecological Studies, 2006.

[2] S. Archibald and J. Bond. Growing tall vs growing wide: tree architecture and allometry of Acacia karroo in forest, savanna and arid environments. Oikos, 103:3-14, 2003.

[3] J. Belsky, W. Carson, C. Jensen, and G. Fox. Overcompensation by plants : herbivore optimisation or red herring ? Evolutionary Ecology, (7):109-121, 1993.

[4] J. Bond and J. Keeley. Fire as a global 'herbivore': the ecology and evolution of flammable ecosystems. Trends in Ecology and Evolution, 20(7):387-394, 2005.

[5] P. Brain, S. Harris, and R. Barnes. Leaf peroxidase types in Acacia karroo hayne (acacieae, leguminosae) : a rangewilde study. Silvae Genetica, (46):88-94, 1997.

[6] S. Cooper, M. K. Owens, D. Spalinger, and T. Ginnett. The architecture of shrubs after defoliation and the subsequent feeding behavior of browsers. Oikos, 100:387-393, 2003.
[7] P. Cournède, M. Kang, A. Mathieu, J. Barczi, H. Yan, B. Hu, and P. de Reffye. Structural Factorization of Plants to Compute their Functional and Architectural Growth. Simulation, 82(7):427-438, 2006.

[8] J. Dangerfield, J. Perkins, and J. Kaunda. Shoot characteristics of Acacia tortilis (forsk.) in wildlife and rangeland habitats of botswana. African Journal of Ecology, 34:167-176, 1995.

[9] P. de Reffye, E. Heuvelink, D. Barthélémy, and P. Cournède. Plant growth models. In Ecological Models. Vol. 4 of Encyclopedia of Ecology (5 volumes), pages 2824-2837. Jorgensen, S.E. and Fath, B., elsevier (oxford) edition, 2008.

[10] D. Fornara. Ungulate browsing as an ecosystem process: browser-plant-soil interactions in a southern African savanna. PhD thesis, Pretoria University, 2005.

[11] J. Gignoux, J. Clobert, and J. C. Menaut. Alternative fire resistance strategies in savanna trees. Oecologia, 110(4):576$583,1997$.

[12] I. Gourlay, J. Smith, and R. Barnes. Wood production in a natural stand of Acacia karroo in zimbabwe. Forest Ecology and Management, 88:289-295, 1996.

[13] Y. Guo, Y. Ma, Z. Zhan, B. Li, M. Dingkuhn, D. Luquet, and P. de Reffye. Parameter optimization and field validation of the functional-structural model greenlab for maize. Annals of Botany, 97:217-230, 2006.

[14] D. Hermes and W. Mattson. The dilemma of plants: to grow or defend. The quarterly review of biology, 67, 1992.

[15] F. Howaida and K. Krzywinski. Environmental effects on morphology of Acacia tortilis group in the red sea hills, north-eastern sudan and south-eastern egypt. Forest Ecology and Management, 212:367-375, 2005.

[16] V. Letort, P. Cournède, A. Mathieu, P. de Reffye, and T. Constant. Parametric identification of a functional-structural tree growth model and application to beech trees Fagus sylvatica. Functional Plant Biology, 35(10):951-963,, 2008.

[17] A. Mathieu, P. Cournède, V. Letort, D. Barthélémy, and P. de Reffye. A dynamic model of plant growth with interactions between development and functional mechanisms to study plant structural plasticity related to trophic competition. Annals of Botany, In Press, 2009.

[18] P. Scogings and K. Mopipi. Effect of water, grass and $n$ on responses of Acacia karroo seedlings to early wet season simulated browsing : Aboveground growth and biomass allocation. Journal of Arid Environments, 72:509-522, 2008.

[19] J. Stave, G. Oba, A. Eriksen, I. Nordal, and S. N.C. Seedling growth of Acacia tortilis and faidherbia albida in response to simulated groundwater tables. Forest Ecology and Management, 212:367-375, 2005.

[20] M. Uriarte, C. Canham, and R. Root. A model of simultaneous evolution of competitive ability and herbivore resistance in a perennial plant. Ecology, 83(10):2649-2663, 2002. 